\title{
Household Decision Making Process of Rural Women in Bangladesh
}

\author{
Syed Muhammad Sajjad Kabir ${ }^{1}$, AKM Shadika Jahan ${ }^{2}$ \\ ('Assistant Professor, Department of Psychology, University of Chittagong, Chittagong-4331) \\ $\left({ }^{2}\right.$ Library Officer, Asian University for Women, M M Ali Road, 20/A, Chittagong)
}

\begin{abstract}
Most of the women in Bangladesh are not empowered to participate in social, economical, and political decision-making process of the country, which is one of the important elements of women empowerment. Within this context the study is designed mainly to identify the areas of participation of women in household decision making and contributing factors of their participation level as well. The specific objectives of the study are to: (a) identify the area of women participation in household decision making (b) identify the significant factors influencing the participation of rural women in decision making processes, (c) measure the degree of participation of women in different areas of household decisions. Raichow village of Comilla Sadar Upazila was purposively selected as the sample for the study. Selected respondents (100) were interviewed using a semi-structured questionnaire. It was found that women participation in joint decision is comparatively higher (above 50\%) in house making/repair, family planning, education of son/daughter, purchase of household goods, treatment of family members and membership in local institutions. On the contrary, the percentage of women's alone decision in presence of household head was rarely observed (highest in family planning only $15.5 \%)$. It has been also observed that in the absence of household head/husband, women's responsibility in the family increased. In the Raichow village, most of the women took household related decisions in absence of household head/husband. The correlation coefficient is significant between women decision level and their age (0.257; $\alpha=0.05)$ and education (0.206; $\alpha=0.10)$; but not significant relationship was found between women decision level and their income. That means women's age and education is positively related to their decision making level.
\end{abstract}

Keywords - Household decision-making, Rural Women, Women Empowerment

\subsection{Statement of the Issue}

\section{Introduction}

In Bangladesh, women constitute about $49 \%$ of the total population. But various indicators reveal that the status of women is much lower than that of men. The involvement of women is mainly confined to the household works like child rearing, cooking, dish washing, post harvesting activities of crops, etc. and they are not adequately involved in household decision making process. Disparities between men and women in education, health, employment and income opportunities, control over assets, personal security and participation in household decision making process as well as political process reveal that women are deprived and less empowered, which limits the country's ability to achieve its full potential (Biswas, 2004 ${ }^{[1]}$ ). Education is one of the most influencing factors for increasing participation of women in household decision-making process. Here it can be mentioned that the national literacy rate of women was $48.82 \%$, while the rate was $58.48 \%$ for men in the year 2006 (BBS, 2007 $7^{[2]}$ ). Rural women are better savers and their credit repayment behavior is better. But lack of appropriate management capability, low literacy rate and poor health and nutritional status of women are the main obstacles on the way of rapid socio-economic progress of them. Therefore, emphasis should be given to their income earning, education, low birth rate and nutritional improvement and these may be considered as an appropriate package for involving women in development (WID).

The rural women in Bangladesh are termed as the "hard working poor", yet their contribution to agriculture and related activities is hardly recognized. Employment, self or wage and others opportunity for rural women is very much limited, whether they are literate or illiterate, skilled or unskilled, young or old, poor or middle class. They bear hard life at home and also in the area of self-employment. Actually they are deprived, exploited, discriminated in agricultural and non-agricultural employments (Ara and Khan, 2005 ${ }^{[3]}$ ). Women are at the bottom of the pay and power scale in agriculture; they are employees not employers, unpaid showers, reapers and bread makers, not bread earners on the family farm (Seager and Olson, $1986^{[4]}$ ).

In fact the extent of participation is determined by various factors like boldness of the women to express opinion, awareness of their rights and share of contribution to the family income. In Bangladeshi culture women are generally allowed to participate to take decision jointly with their husbands and other family members on their children's education and marriage related matters (The Journal of Geo-Environment, 2004:54). 
But in the development arena women should supposed to participate in household decision-making process. In fact, this remarkable change in women access to such crucial aspects of decision making is greatly appreciated and a salient indication towards the progress of women empowerment. Empowerment of women in the society and in the state as a whole will not be ensure until and unless they can take part effective role in decisionmaking process at all level.

Participation in household decision-making process under the study refers to the extent of women's participation in planning and executing decisions regarding household expenditure, child-welfare, reproductive health, farming and socio-political matters in coordination with other family members. Few studies were conducted mainly in the areas of health, education, training etc (Banu, 1996 ${ }^{[5]}$; Khan, 2000 ${ }^{[6]}$; Kabir, $1996^{[7]}$ ). There is also lack of studies to know the status of women's participation in decision-making process at household level. This study is an attempt to assess the participation of women in household decision-making process.

\subsection{Objectives}

The general objective of the study was to assess women's participation in household decision-making processes of rural areas in Bangladesh. The specific objectives of the study are to:

i. $\quad$ identify the area of women participation in household decision making;

ii. identify the significant factors influencing the participation of rural women in decision making processes; and

iii. measure the degree of participation of women in different areas of household decisions.

\subsection{Justifications}

Decision-making is always been an important part in social setting. For understanding the process of decision-making it is important to understand as to how people make decisions and the factors influence the decisions. Studies (Srinivasan and Sharan, 2005 ${ }^{[8]}$ ) show that decisions are not made in isolation but they are the products of influence and confluence of social correlates. These studies emphasize that the decisions are not made in isolation but in consultation with other members. This raises an important question of how individual's choices no longer of his or her own but socially constructed. This emphasizes how individuals consult with others while making decisions. From this it is clear that the matters relating to health are also decided in consultation with the other members of the community. From this we can understand how decision-making is important in a family setting for an individual. Literatures on social network (Srinivasan and Sharan 2005) have suggested the importance of social interaction on health decisions. They also suggest social networks help the individuals to learn to handle problematic situations. In National Family Health Survey (NFHS-3, 2005-06 ${ }^{[9]}$ ), under "Women's empowerment and demographic and health outcomes" discussed the importance of wife's participation in household decision- making. According to NFHS- 3(2005-06), it is important to study the women's participation in household decision making is an important issue for understanding the status and empowerment of women in society and within their households.

The participation of women in decision-making process is an essential precondition for the elimination of world poverty and the upholding of human rights (DFID, 2000 ${ }^{[10]}$ ), in particular at the individual level, it helps building a base for social change. In Bangladesh, women constitute about half of the total population of which 80 percent live in rural areas (BBS, 2001: $21^{[11]}$ ). But their status has been ranked the lowest in the world on the basis of twenty indicators related to health, marriage, children, education, employment and social equality (NCBP, 2000: $27^{[12]}$ ). It is a well established fact that in a patriarchal society like Bangladesh, women are ascribed a lower status as men who have the sovereign power to control households and society as a whole, while women are often excluded in their homes (Balk, 1997: $4^{[13]}$ ). The World Bank study in Bangladesh highlights that women have limited role in household decision-making, limited access and control over household resources (physical and financial assets), low level of individual assets, heavy domestic workloads, restricted mobility and inadequate knowledge and skills that leading to women's vulnerability (Sebstad and Cohen 2002: $44^{[14]}$ ).

In Bangladesh, very few attempts have been made to assess about the participation of women in decision-making process at household level activities. Thus the study would help identify the problems and prospects of the rural women in decision-making process at household level. It was expected that the study would investigate the problem relating to participation of rural women in household decision-making process. The study will also identify the factors that influencing in the decision-making process at household level. Finally, the outcomes of the study would be helpful to the policy planners for designing project to address the problem of women in decision-making process at household level. 


\subsection{Selection of Study Area}

\section{Methodology}

Raichow village of Comilla Sadar Upazila was purposively selected for the study. Thus, one hundred households were selected randomly from Raichow village of Sadar Upazila of Comilla district in Bangladesh.

\subsection{Methods of Data Collection}

Data for the study were collected from both primary and secondary sources. Primary data were collected from rural women of the Raichow village of Comilla Sadar Upazila. For collecting primary data a structured interview schedule was developed with combination of both closed and open-ended questions. Secondary data were collected from books, journals, office records of CVDP and other published documents. Both quantitative and qualitative data were used to fulfill the objectives of the study. Researchers' observations were also incorporated in the study. The researchers themselves were involved to collect the data.

\subsection{Data Processing and Data Analysis}

SPSS (Version-16) program was used for analyzing the data. Collected data were presented in tables, graphs and charts. Simple statistical tools such as, percent, average, correlation, regression were used to interpret findings of the study. Data were processed by the researchers themselves. The study team consisted of two members. Composite score was used for analyzing the data.

\subsection{General Information of the Respondents and Their Household \\ III. Results And Discussion}

\subsubsection{Household Size and Sex Ratio}

According to the Village Information Book (BIB) of Comprehensive Village Development Programme (CVDP), total household in Raichow village was 267 and the total population was 1446 where male was 726 and female was 720 . The one hundred households were selected for the study and total household members were 380 , family size 5.38, where national household size is 4.9 and sex ratio 109 . This implies that there were about 109 male people for each 100 female people.

3.1.2 Marital Status of the Household Members

Marital status is one of the most important factors for the rural women for participation in decision-making processes at household level. Marital status was classified into five categories: unmarried, married, widow, divorcee, and separate.

Table 1

Marital Status of the Household Members

\begin{tabular}{lccc}
\hline Marital Status & $\begin{array}{c}\text { Male } \\
(\%)\end{array}$ & $\begin{array}{c}\text { Female } \\
(\%)\end{array}$ & $\begin{array}{c}\text { Total } \\
(\%)\end{array}$ \\
\hline Unmarried & 54.5 & 46.7 & 50.8 \\
Married & 45.5 & 50.0 & 47.6 \\
Widow & - & 2.2 & 1.1 \\
Divorced & - & 0.5 & 0.3 \\
Separate & - & 0.5 & 0.3 \\
\hline Total & 100.0 & 100.0 & 100.0 \\
\hline
\end{tabular}

[Source: Field Survey, 2009]

The table shows that 50.8 per cent was found unmarried and 47.6 percent was married of the total population. Widow, divorced and separate together comprised only about 1.7 percent.

\subsubsection{Education}

Education is one of the most important aspects of human life for achieving success. In this regard, different studies revealed that educational attainment particularly women's education has significant effect on decision-making processes at household level. This study followed the definition of literacy used in 2001 population census i.e. a person aged seven years and adult education aged fifteen years who is able to write letter can be considered as literate. It appears that literacy rate in the study village was about 79.9 per cent, which was found higher than the national level. 


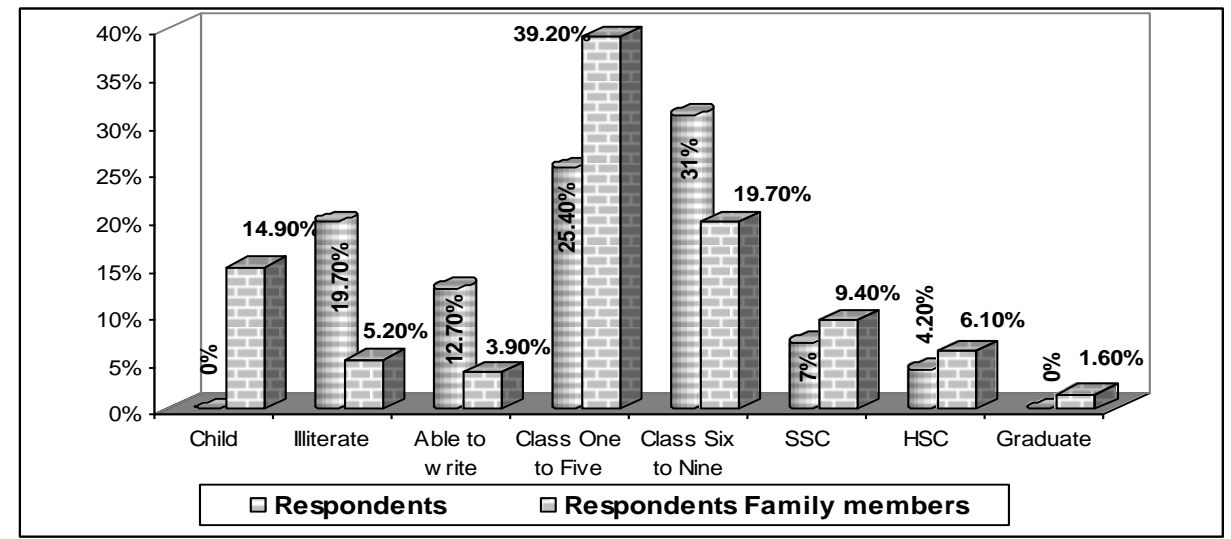

Figure 1

Education level of the respondents and their family member

But it was found in the PRA that the educations of the village women were not up to the desired level. The parents or guardians did not show interest to educate their daughter. When their daughter studied in the high school level, tried to arrange marriage.

\subsubsection{Age Distribution}

The Table indicates that percentage of respondents under 25 years of age was about 22.5 per cent where it was 68.9 per cent in case of household members. Percentage of population under the age group of 26 to 35 and 36 to 45 was 35.2 and 25.4 respectively.

Table 2

Age Distribution of the Respondents and their HH Members

\begin{tabular}{ccccc}
\hline \multirow{2}{*}{ Age } & \multicolumn{2}{c}{ No. of Respondents } & \multicolumn{2}{c}{ Household members } \\
\cline { 2 - 5 } & No. & Percentage $(\%)$ & No. & Percentage $(\%)$ \\
\hline Up to 25 & 16 & 22.5 & 213 & 68.9 \\
26 to 35 & 25 & 35.2 & 29 & 9.4 \\
36 to 45 & 18 & 25.4 & 16 & 9.4 \\
46 to 55 & 6 & 8.5 & 12 & 5.2 \\
56 to 65 & 6 & 8.5 & 10 & 3.9 \\
66 and above & 0 & 0 & 309 & 3.2 \\
\hline Total & 71 & 100.0 & & 100.0 \\
\hline
\end{tabular}

[Source: Field Survey, 2009]

\subsubsection{Involvement of Respondents with Local Institutions}

Involvement of women with local institutions like Co-operative societies and NGOs has positive impact on their self-awareness and decision-making as well as empowerment. It encouraged the respondents to take initiative for income generating activities to raise their household income.

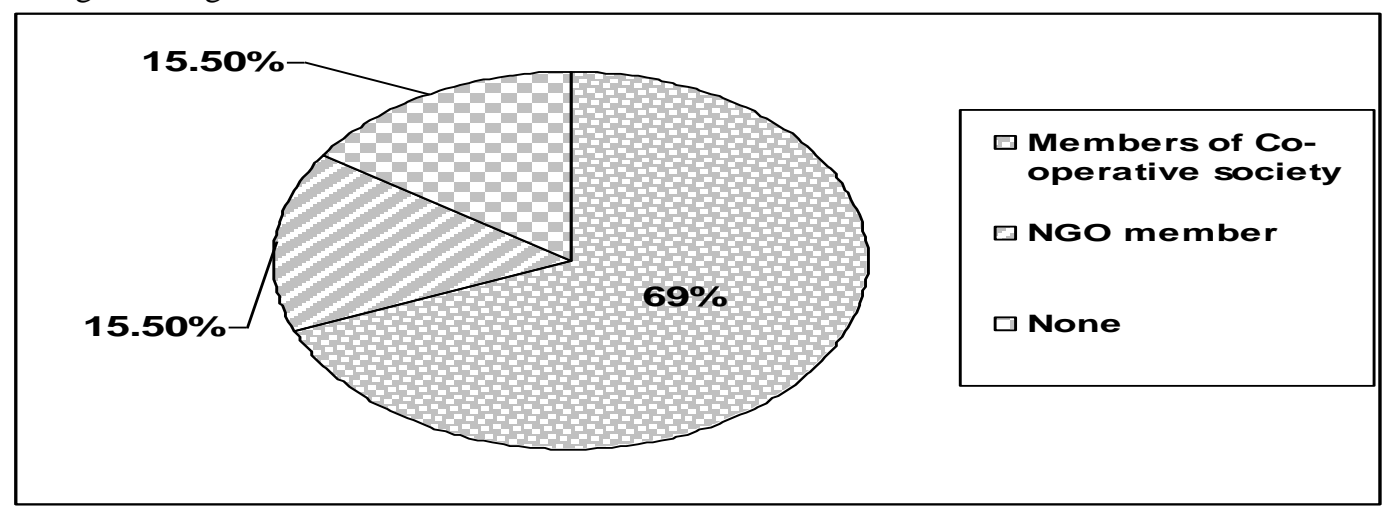

Figure 2

Involvement of the respondents in different organizations 


\subsubsection{Occupational Pattern of the Respondents}

Occupational pattern is one of the most important indicators of economic status, which influence in decision- making process at household level. It was found that almost all respondents were housewives (97.2\%). Women's position in occupation was considered as one of the determinant factors of participation in household decision.

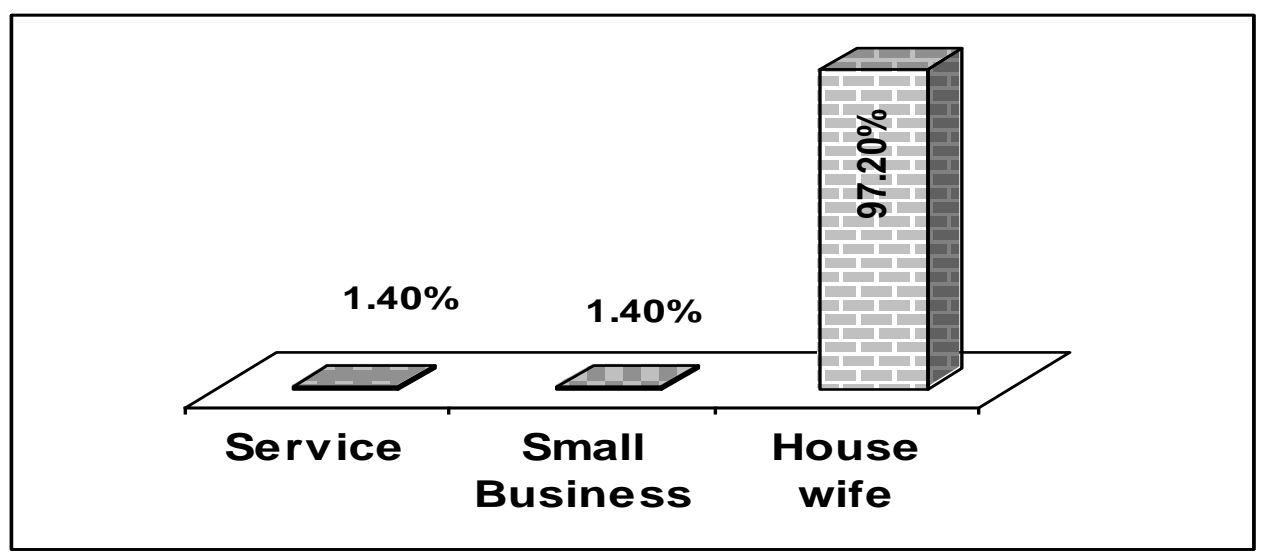

Figure 3

Occupational pattern of the respondents

\subsubsection{Land Ownership Pattern}

Land ownership determines the economic and social conditions of rural people. In Bangladesh, male members of the household occupied most of land, while very few women possess land. Women having land feel more secured, which increase their participation in decision-making process of the household activities (Biswas, 2004).

Table 3

Land Ownership Pattern of the Respondents Household

\begin{tabular}{lcccc}
\hline \multirow{2}{*}{\multicolumn{1}{c}{ Land ownership }} & \multicolumn{2}{c}{ Land of Household Head } & \multicolumn{2}{c}{ Land of Respondents } \\
\cline { 2 - 5 } & No. & Percentage $(\%)$ & No. & Percentage $(\%)$ \\
\hline Landless $(0.00-0.49)$ & 55 & 77.5 & 6 & 8.5 \\
Marginal $(.50-.99)$ & 9 & 12.7 & 1 & 1.4 \\
Small $(1.00-2.49)$ & 4 & 5.6 & - & - \\
Medium $(2.50-7.49)$ & 2 & 2.8 & - & - \\
Large $(7.50$ and Above $)$ & 1 & 1.4 & - & - \\
\hline Total & 71 & 100.0 & 7 & 9.9 \\
\hline
\end{tabular}

[Source: Field Survey, 2009]

The Table indicates that out of total (71) respondents only 7 had land in their own name. The rest 64 respondents had no land.

\subsubsection{Income of the Respondents and HH Members}

Income is one of the most important indicators of socio-economic status of people. In this table, income from different sources of households like agriculture, business, aquaculture, poultry, livestock, handicrafts, and foreign remittances were considered. The Table shows that the highest income range (100001 and above) was 38 per cent, because of foreign remittances.

Table 4

Annual Income Distribution Pattern of the Respondents Household

\begin{tabular}{ccc}
\hline Income Group (Tk) & No. of Respondents & Percentage $(\%)$ \\
\hline 25001 to 50000 & 14 & 19.72 \\
50001 to 75000 & 16 & 22.53 \\
75001 to 100000 & 14 & 19.72 \\
100001 and above & 27 & 38.03 \\
\hline Total & 71 & 100.0 \\
\hline
\end{tabular}


Women's status in household is mainly depending on their income earning ability. Women participation in income earning activity can increase household income as well as their control on household decision-making process. But women had very little employment opportunity due to inadequate education (Biswas, 2004).

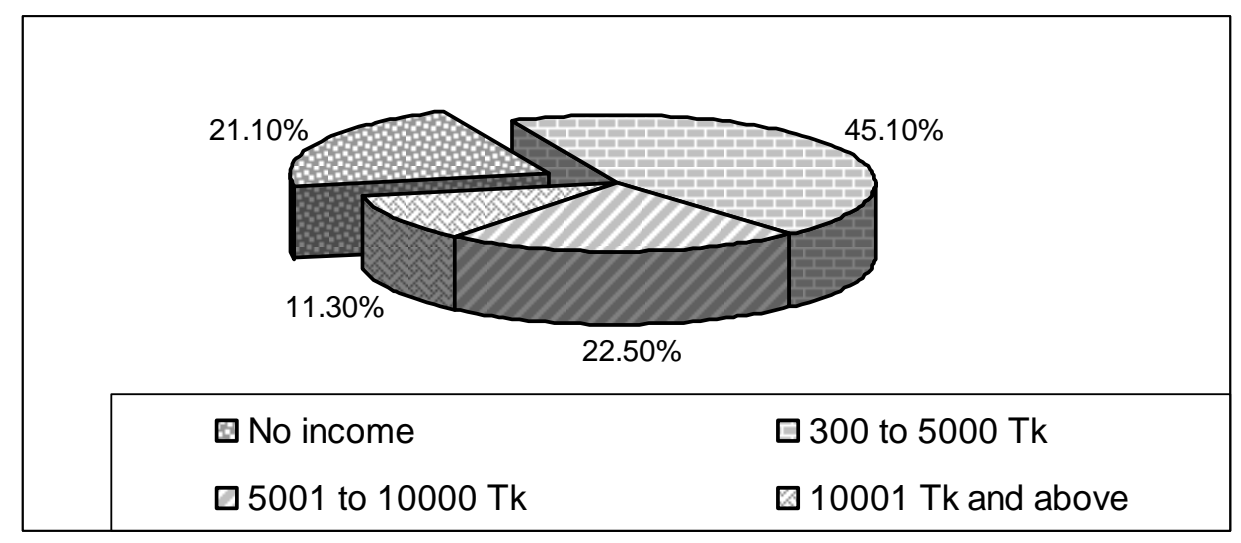

Figure 4

Annual income distribution pattern of respondents

\subsection{Area of Household Decisions}

Women's decision-making power within their household was measured by the extent of their role in making decisions regarding several issues of the household. A total of 13 areas were considered in the areas of women's participation in household decisions, which are: cultivation; house building/repair; land purchase/sale ; land mortgage; family planning; marriage of son/daughter; education of son/daughter; household goods purchase; treatment of family; other expenditure of family; membership in local institutions; crop harvesting and preservation and crop selling. It was found in the PRA that a large number of household head/male person of the study area were working in different places out of village both in country and abroad. Considering this case, the questionnaire was divided in two parts: one for the household head, where the household head was present, and another while the household head was absent. In order to measure the level of participation in each of the mentioned areas, the woman was asked whether she could make household related decisions alone or jointly with her husband/other family members or not at all. The responses were given score 2 for each of the above issues if she took decision alone, score 1 if she participate in decision i.e. jointly and score 0 if she did not take decision at all. In Bangladesh, women have very limited access in decision-making process at household level. Generally most of the decisions were taken by the male. In order to asses the areas of women's participation in decision making, 13 issues regarding household related activities were asked and the information is presented in the following Table.

Table 5

Percentage Distribution of Respondents' Decision Making Process in Presence of Household Head (HH) SN Areas of Decision Making

Decision Making when $\mathrm{HH}$ is Present

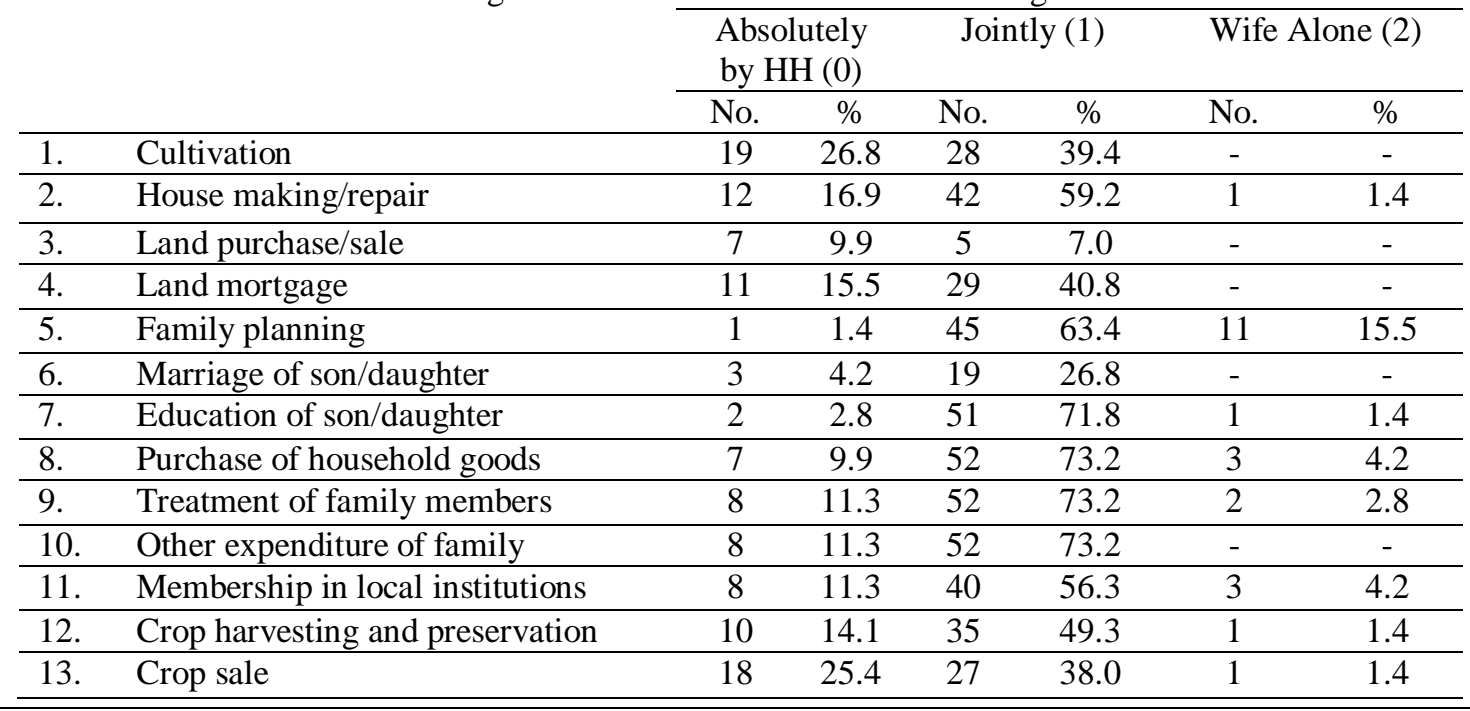


[Source: Field Survey 2009]

The above Table shows that women's involved in joint decision-making in almost all of the thirteen areas in presence of household head. Among them their participation is comparatively higher (above 50\%) in house making/repair, family planning, education of son/ daughter, purchase of household goods, treatment of family members and membership in local institutions. On the contrary, the percentage of women's alone decision in presence of household head is negligible in all the areas.

\subsubsection{Level of Participation in Joint Decision}

The Table indicates that women involved joint decision in almost all of the thirteen areas but it differed in level of participation. According to composite scores their participation level was comparatively better in family planning (80.56\%), education of son/ daughter (59.21\%), purchase of household goods (53.92\%), treatment of family members (56.25\%), and membership in local institutions (65.63\%); which showed high level of participation in household decision-making process.

Table 6

Percentage Distribution of Respondents' Joint Decision Making Level in Presence of Household Head (HH)

\begin{tabular}{|c|c|c|c|c|c|c|c|c|c|c|c|c|c|}
\hline \multirow[b]{3}{*}{$\mathrm{SN}$} & \multirow{3}{*}{$\begin{array}{l}\text { Areas of } \\
\text { Decision } \\
\text { Making }\end{array}$} & \multirow{2}{*}{\multicolumn{2}{|c|}{ Respondents }} & \multicolumn{8}{|c|}{ Participation Level of Women in Joint Decision } & \multirow{3}{*}{ 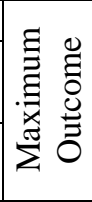 } & \multirow{3}{*}{ 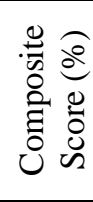 } \\
\hline & & & & \multicolumn{2}{|c|}{$\begin{array}{l}\text { Little } \\
(1)\end{array}$} & \multicolumn{2}{|c|}{ Medium (2) } & \multicolumn{2}{|c|}{$\begin{array}{l}\text { High } \\
(3)\end{array}$} & \multicolumn{2}{|c|}{$\begin{array}{c}\text { Very High } \\
(4)\end{array}$} & & \\
\hline & & No. & $\%$ & No. & $\%$ & No. & $\%$ & No. & $\%$ & No. & $\%$ & & \\
\hline 1. & Cultivation & 28 & 39.44 & 7 & 25.0 & 17 & 60.71 & 4 & 14.29 & - & - & 112 & 47.32 \\
\hline 2. & $\begin{array}{l}\text { House } \\
\text { making/repair }\end{array}$ & 42 & 59.15 & 15 & 35.71 & 17 & 40.48 & 10 & 23.81 & - & - & 168 & 47.02 \\
\hline 3. & $\begin{array}{l}\text { Land } \\
\text { purchase/sale }\end{array}$ & 5 & 7.04 & 4 & 80.0 & 1 & 20.0 & - & - & - & - & 20 & 30.0 \\
\hline 4. & $\begin{array}{l}\text { Land } \\
\text { mortgage }\end{array}$ & 29 & 40.45 & 10 & 34.48 & 13 & 44.83 & 6 & 20.69 & - & & 116 & 46.55 \\
\hline 5. & $\begin{array}{l}\text { Family } \\
\text { planning }\end{array}$ & 45 & 63.38 & 2 & 4.44 & 6 & 13.33 & 17 & 37.79 & 20 & 44.44 & 180 & 80.56 \\
\hline 6. & $\begin{array}{l}\text { Marriage of } \\
\text { son/daughter }\end{array}$ & 19 & 26.76 & 3 & 15.79 & 6 & 31.58 & 10 & 52.63 & - & - & 76 & 59.21 \\
\hline 7. & $\begin{array}{l}\text { Education of } \\
\text { son/daughter }\end{array}$ & 51 & 71.83 & 7 & 13.73 & 19 & 37.25 & 25 & 49.02 & - & - & 204 & 58.82 \\
\hline 8. & $\begin{array}{l}\text { Purchase of } \\
\text { household } \\
\text { goods }\end{array}$ & 52 & 73.24 & 13 & 25.0 & 21 & 40.38 & 17 & 32.70 & 1 & 1.92 & 208 & 53.92 \\
\hline 9. & $\begin{array}{l}\text { Treatment of } \\
\text { family } \\
\text { members }\end{array}$ & 52 & 73.24 & 5 & 9.62 & 31 & 59.61 & 14 & 26.92 & 2 & 3.85 & 208 & 56.25 \\
\hline 10. & $\begin{array}{l}\text { Other } \\
\text { expenditure } \\
\text { of family }\end{array}$ & 52 & 73.24 & 19 & 36.54 & 22 & 42.31 & 10 & 19.23 & 1 & 1.92 & 204 & 47.55 \\
\hline 11. & $\begin{array}{l}\text { Membership } \\
\text { in local } \\
\text { institutions }\end{array}$ & 40 & 56.34 & 4 & 10.0 & 11 & 27.5 & 21 & 52.5 & 4 & 10.0 & 160 & 65.63 \\
\hline 12. & $\begin{array}{l}\text { Crop } \\
\text { harvesting } \\
\text { and } \\
\text { preservation }\end{array}$ & 35 & 49.30 & 15 & 42.86 & 17 & 48.57 & 3 & 8.57 & - & - & 140 & 41.43 \\
\hline 13. & Crop sale & 27 & 38.03 & 9 & 33.33 & 16 & 59.26 & 2 & 7.41 & - & - & 108 & 43.32 \\
\hline
\end{tabular}

[Source: Field Survey 2009]

This Table also shows that women participation in decision of some important areas like cultivation, land purchase/ sale, crop harvesting/sale was found very low.

\subsubsection{Level of Participation in Absence of Household Head}

Delegation of responsibility to women helps them to be more empowered for decision- making (Kothari, 2004 ${ }^{[15]}$ ). It has been observed that in the absence of household head/ husband, women's responsibility 
in the family increased. In the study area, nine household was found, where decision-making by the women was higher in absence of household head/husband. According to composite scores, house building/repair (77.78\%), land mortgage $(61.11 \%)$, education of son/daughter $(88.89 \%)$, household goods purchase $(94.44 \%)$, treatment of family members $(88.89 \%)$, other family expenditure (94.44\%) and membership in local institutions $(83.33 \%)$.

Table 7

Percentage Distribution of Respondents' Decision Making Level in Absence of Household Head (HH)

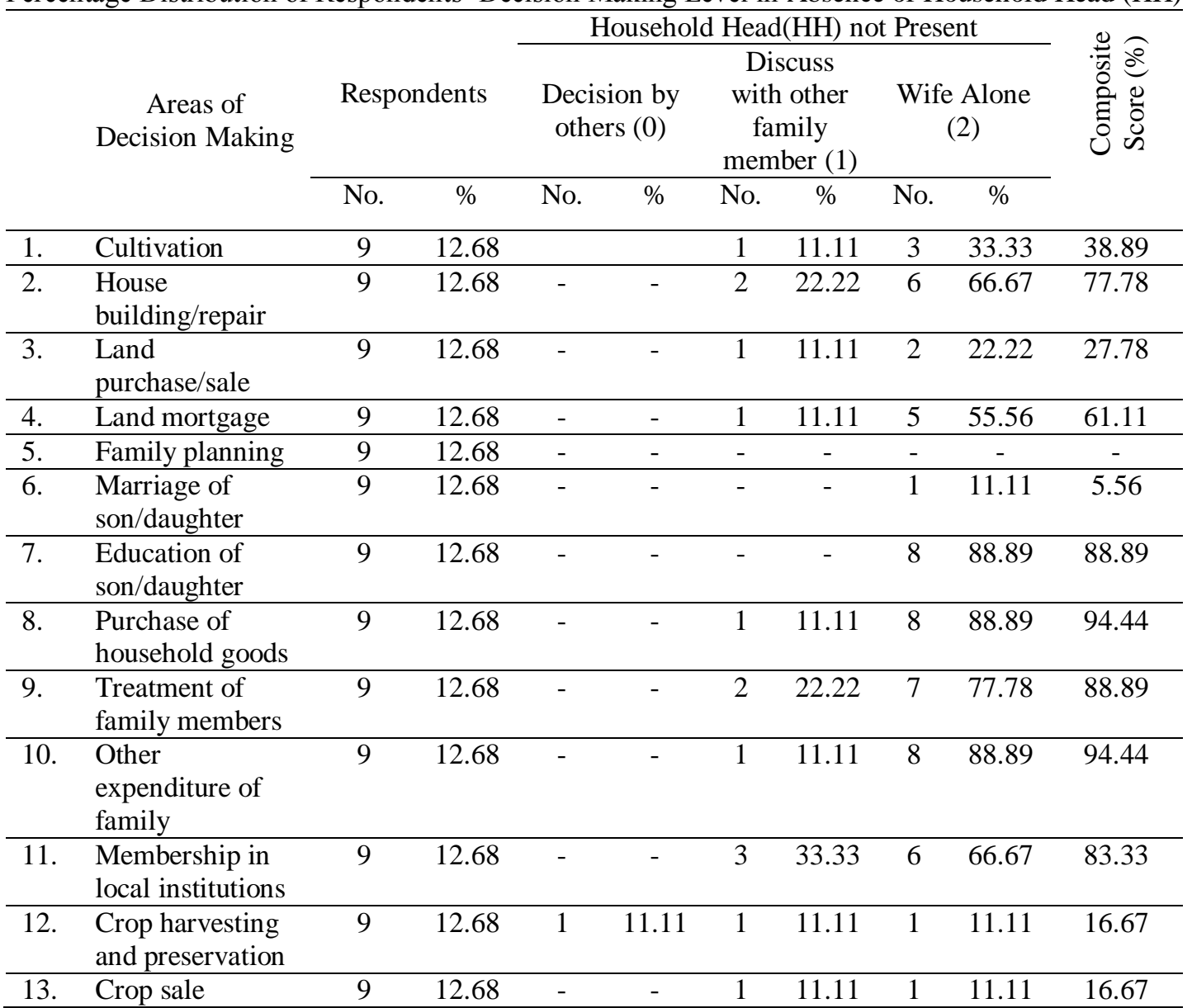

[Source: Field Survey 2009]

\subsection{Related Factors of Women's Decision Making at Household Level}

The Table indicates that the correlation coefficient is significant between women decision level and their age (at the 0.05 level) and education (at the 0.10 level); but not significant between women decision level and their income. That means women's age and education is positively related to their decision making level.

Table 8

Correlations Coefficients of Contributing Factors of Women's Decision at Household Level

\begin{tabular}{lccc}
\hline \multicolumn{1}{c}{ Decision } & Income & Age \\
\hline Decision & & & \\
Income & .085 & .100 & $.206^{* *}$ \\
Age & $.257^{*}$ & .154 & .135 \\
Education & .135 Correlation is significant at the 0.10 level (2-tailed).
\end{tabular}

\subsection{Respondents' Perception about Problems of Women's Participation in Decision Making and Their Solutions}

Identification of the participation in decision-making problem at household level is one of the crucial aspects to develop some strategies. In this regard, respondents were asked to mention some problems related to 
their decision-making. Some of the respondents mentioned some problems in household decision-making process as follows -

\begin{tabular}{llll}
\hline SN & Problems in Decision Making & No. of Respondents & Percentage \\
\hline 1. & Lack of education & 21 & 29.78 \\
2. & Women are deprived of their right & 5 & 7.04 \\
3. & Lack of women awareness & 4 & 5.63 \\
4. & Lack of income & 9 & 12.68 \\
5. & Women opinion has no value & 14 & 19.72 \\
6. & Lack of social awareness & 4 & 5.63 \\
\hline
\end{tabular}

[Source: Field Survey 2009]

Out of 71 respondents, only 29.78 per cent mentioned that due to lack of education the rural women could not perform their role in any kind of decision-making process at household level. 19.72 percent respondents mentioned that women had no scope in household decision- making process.

In order to enhance women's participation in decision-making at household level, respondents' were asked to make some recommendations. The suggestions of the enhancing women's participation are as follows -

\begin{tabular}{llll}
\hline SN & Suggestions & No. of Respondents & Percentage \\
\hline 1. & Women should be educated & 23 & 32.39 \\
2. & Women should be aware of their rights & 4 & 5.63 \\
3. & Awareness of women should increased & 11 & 15.49 \\
4. & $\begin{array}{l}\text { Should involve in income generating } \\
\text { activities (IGA) }\end{array}$ & 19 & 26.76 \\
& $\begin{array}{l}\text { Household head should provide scope in } \\
\text { decision-making }\end{array}$ & 16 & 22.53 \\
\end{tabular}

[Source: Field Survey 2009]

About 32.39 per cent respondents suggested that women's education was the first priority for their household decision-making. The level of education should be increased that would help to get employment and involve in income generating and thus created scope in decision-making. It was also pointed out that in order to increase participation in decision making, men should aware of the women rights, education, opinion and income generating activities.

\section{Conclusion and Recommemdation}

Women have made important contributions in almost every aspects of our society from the time immemorial. Historically the work of women in Bangladesh was mostly confined to the homestead due to the culture, religion and social restrictions. However, with the great declining of the socio-economic situation of the country the women are breaking through the traditional norms and coming forward to participate in the development activities outside their homestead. Currently, women in Bangladesh have an anchoring role in the management of their families as well as equal participation in different economic activities like crop production, post-harvest activities, poultry rearing, management of livestock and fisheries.

It was found in the PRA that in rural societies of Bangladesh, women are usually not permitted to interact with men other than their direct close family members and as a result, they have only limited access to development personnel. Spatial mobility is another important factor in women's social, economic and political empowerment. A mobility map analysis shows that rural wives generally visit their natal houses to meet their old or sick parents, to get financial or any other kind of support during crisis periods. They go to the town to buy clothes especially for their children in local town. They visit the health centre mainly for the treatment of their sick children or for their own reproductive health care. Only a very few women go to the crop fields, mainly for activities like weeding or collecting fodder and firewood. It is rare for a woman to cultivate crops in the field due to the restrictions imposed by cultural and religious norms. Thus, the lack of women's physical mobility deprives them of getting better livelihood opportunities. However, the study variables do not explain the whole situation of women's participation at household level. There are several quantitative and qualitative factors, which could contribute to women's participation, particularly qualitative ones, for instance, religious belief, household type, husbands' attitudes etc. Therefore, the need for implementing holistic strategies for women (particularly in the areas of human resource development) that may enhance women's status and quality of life in the face of extremely disabling social conditions.

Based on empirical results and discussion, the overall conclusion of this study is that the level of women's empowerment is not satisfactory at the households' level. It also highlights the fact that formal and 
non-formal education is the most influential factor that enhances women's participation. In contrast, the traditional beliefs, attitudes and practices are deeply entrenched in women's lives that hinder their participation. To move forward, some concrete steps need to be undertaken by the major intervening agencies, namely governmental organizations (GOs), non-governmental organizations (NGOs), women's organizations (WOs) and other stakeholders (private initiatives, civil society etc.) aimed at stimulating the process of female participation. Interventions should be in the nature of legislative, planning, programme or structural steps to provide greater opportunities for the sustainable development of women at all levels and to reduce discriminatory practices against women as well as all types of gender-based stereotypes. However, strategies to combat the lack of participation at households level must address not only the immediate needs of rural women (practical gender need) but must also focus on the root cause of women's powerlessness (strategic gender need). The following recommendations were made in the light of above discussion and study findings -

(a) Educational level of rural women should be increased to enhance their participation in decision-making process at households' level.

(b) It is important to involve the rural women in different income generating activities (IGAs) besides their regular household activities to enhance their level of participation in decision-making process.

(c) In unemployment ridden country like Bangladesh, where most of the women have very low level of education, creation of new employment opportunities are difficult particularly in rural context. In this regard, efforts should be taken both by the Government organization and NGOs to come forward to create employment through micro-credit and providing vocational training on handicrafts, sewing, poultry and livestock, vegetable gardening, etc.

(d) Awareness raising programme about the importance of women's participation should be made both for male and female. In this regard, social and religious leaders, community level organizations, Department of Women's Affairs, NGOs and mass media can play vital roles.

Family is the oldest educational institution. So, it is important to ensure women's participation in household decision-making at the very beginning. Among the different influencing factors, decision-making is one of the important factors for empowerment of women. It was found in the study in most areas of household decisionmaking, the participation of women is still far from the expectation. It is necessary to improve their participation in decision-making to enhance their empowerment as well as overall development.

\section{References}

[1] T. K. Biswas, Women's Empowerment and Demographic Change, Comilla: BARD, 2004

[2] BBS, Statistical Yearbook of Bangladesh, Bangladesh Bureau of Statistics, Government of the People's Republic of Bangladesh, 2007.

[3] F. Ara and M. R. Khan, Women in Agriculture: Bangladesh Perspective, Empowerment, A Journal of Women for Women, $12,2005$.

[4] J. Seager and A. Olson, Women in the World: On International Atlas, New York, 1986.

[5] T. Banu, The Impact of Training on Rural Women's Empowerment in Bangladesh, Comilla: BARD, 1996.

[6] A. H. Khan, et al. Major Ongoing WID Projects on Rural Women, Comilla, BARD, 2000.

[7] N. N. Kabir, Impact of Income, Education, Nutrition and Family Planning Intervention on Women's Development, BARD: Comilla, 1996.

[8] K. Srinivasan and Sharan, Social Networks and Health Decisions: A Case of Two Villages of Tamil Nadu, MPRA Paper 7075, University Library of Munich, Germany, 2005.

[9] NFHS (2005-'06), National Family Health Survey, 3, Bangladesh.

[10] DFID, Report on Poverty Elimination and the Empowerment of Women, UK: Stairway Communications, 2000.

[11] BBS Statistical Yearbook of Bangladesh, Bangladesh Bureau of Statistics, Government of the People's Republic of Bangladesh, 21, 2001 .

[12] NCBP, National Children's Book Project, 27, Bangladesh, 2000.

[13] D. Balk, Change Comes Slowly for Women in Rural Bangladesh: Asia-Pacific Population \& Policy 41: 4. Honolulu, Hawaii (USA): East-West Centre, 1997.

[14] J. Sebstad and M. Cohen, Microfinance, Risk Management, and Poverty, AIMS Paper, Management Systems International, Washington, D.C, 2002.

[15] C. R. Kothari, Research Methodology: Methods and Techniques (2 ${ }^{\text {nd }}$ Edition), New Delhi 110 002, 2004. 